\title{
Radiographic Assessment on Magnetic Resonance Imaging after Percutaneous Endoscopic Lumbar Foraminotomy
}

\author{
Yong AHN, ${ }^{1}$ Woo-Kyung KIM, ${ }^{1}$ Seong Son, ${ }^{1}$ Sang-Gu LEE, ${ }^{1}$ \\ $\mathrm{Yu} \mathrm{Mi}$ JEONG, ${ }^{2}$ and Taeseong $\mathrm{IM}^{2}$ \\ ${ }^{1}$ Department of Neurosurgery, Gachon University Gil Medical Center, Incheon, Korea; \\ ${ }^{2}$ Department of Radiology, Gachon University Gil Medical Center, Incheon, Korea
}

\begin{abstract}
Percutaneous endoscopic lumbar foraminotomy (ELF) is a novel minimally invasive technique used to treat lumbar foraminal stenosis. However, the validity of foraminal decompression based on quantitative assessment using magnetic resonance imaging (MRI) has not yet been established. The objective of this study was to investigate the radiographic efficiency of ELF using MRI. Radiographic changes of neuroforamen were measured based on pre- and postoperative MRI findings. Images were blindly analyzed by two observers for foraminal stenosis grade and foraminal dimensions. The intraclass correlation coefficient (ICC) and $k$ statistic were calculated to determine interobserver agreement. Thirty-five patients with 40 neuroforamen were evaluated. The mean visual analog scale (VAS) score improved from 8.4 to 2.1 , and the mean Oswestry disability index (ODI) improved from 65.9 to 19.2 . Overall, $91.4 \%$ of the patients achieved good or excellent outcomes. The mean grade of foraminal stenosis significantly improved from 2.63 to 0.68. There were significant increases in the mean foraminal area (FA) from 50.05 to $92.03 \mathrm{~mm}^{2}$, in mean foraminal height (FH) from 11.36 to $13.47 \mathrm{~mm}$, in mean superior foraminal width (SFW) from 6.43 to $9.27 \mathrm{~mm}$, and in mean middle foraminal width (MFW) from 1.47 to $78 \mathrm{~mm}(P<0.001)$. Interobserver agreements for preoperative and postoperative measurements were good to excellent with the exception of SFW. In conclusion, foraminal dimensions and grades of foraminal stenosis significantly improved after ELF. These findings may enhance the clinical relevance of endoscopic lumbar foraminal decompression.
\end{abstract}

Key words: endoscopic, foraminotomy, interobserver agreement, magnetic resonance imaging

\section{Introduction}

Lumbar foraminal stenosis is a common pathology causing radiculopathy and back pain. Open paraspinal microdecompression is now a widely used decompression technique that has a success rate of $72 \%$ to $83 \% \cdot{ }^{1-12)}$ However, surgical outcomes of the technique are not as effective as those of intracanal surgery because of complications that include postoperative leg pain and dysesthesia. ${ }^{4,5,7,9,11)}$ Moreover, excessive removal of the facet joint may lead to lumbar segmental instability or back pain. ${ }^{1,11,13,14)}$ To reduce tissue damage, various minimally invasive endoscopic techniques have been developed for foraminal decompression. ${ }^{15-20)}$ The percutaneous endoscopic lumbar discectomy (PELD) technique

Received October 1, 2016; Accepted August 8, 2017

Copyright $\odot 2017$ by The Japan Neurosurgical Society This work is licensed under a Creative Commons AttributionNonCommercial-NoDerivatives International License. for soft disc herniation has been developed with benefits that include minimal tissue traumatization and early recovery. ${ }^{21-24)}$ The effectiveness of PELD has been verified through randomized controlled studies. ${ }^{25-28)}$ Endoscopic decompression for foraminal stenosis, however, is in a nascent stage. Ironically, the transforaminal approach (through the "foraminal window") is more difficult in foraminal decompression than in intracanalicular decompression. The approach to a severely stenotic neuroforamen and thorough decompression has been challenging. We have developed a more practical endoscopic technique to achieve full-scale foraminal decompression using a working channel endoscope. ${ }^{29,30)}$ To our knowledge, there are no relevant studies on radiographic assessments with clinical data after endoscopic lumbar foraminal decompression. Therefore, the objective of this study was to evaluate the efficacy of percutaneous endoscopic lumbar foraminotomy (ELF) radiographically and the clinical outcomes. In this article, we report on postoperative changes in lumbar foraminal 
parameters on magnetic resonance imaging (MRI) using both quantitative and qualitative methods.

\section{Materials and Methods}

\section{Study population}

This retrospective study was conducted after ethical approval from the institutional ethical committee and included 38 consecutive patients who underwent ELF between September 2011 and December 2012. During the two-year follow-up period, three patients $(7.9 \%)$ were lost to follow-up. Therefore, clinical and radiographic data were collected from the remaining 35 patients (40 neuroforamens). Inclusion criteria for ELF were patients with symptomatic lumbar foraminal stenosis despite taking more than six weeks of conservative treatment. All patients underwent selective nerve root blocks that showed only transient effects. The radiographic criteria were moderate to severe foraminal stenosis with perineural fat obliteration or nerve root collapse. ${ }^{29,31,32)}$ Patients with intracanalicular stenosis, definitive segmental instability, or other pathologic conditions such as inflammation, infection, or tumor were excluded.

\section{Surgical technique}

The surgical procedure can be divided into three stages: a safe extraforaminal approach, endoscopic foraminal unroofing, and full-scale delicate foraminal decompression. The procedure is performed under local anesthesia. As premedication, $0.05 \mathrm{mg} / \mathrm{kg}$ midazolam is injected intramuscularly 30 minutes prior to surgery. In the operation room, $0.8 \mathrm{mg} / \mathrm{kg}$ Fentanyl is intravenously administered immediately before surgery, with additional doses if necessary. The level of the conscious sedation can be titrated so that the patient is able to communicate with the surgeon during the procedure. The patient is placed in prone position on a radiolucent table. The skin entry point and approach angle are determined according to the target point and patient's body size. ${ }^{29)}$

Extraforaminal approach under fluoroscopic guidance: The most important objective of this initial step is safe landing of the final working sheath and endoscope in the targeted foraminal zone (Fig. 1A). The target point of the initial needling with an 18-gauge spinal needle is the surface of the facet joint or inferior pedicle, far from the exiting nerve root. Once firmly engaged with the facet, the needle is replaced by a guidewire. A tapered obturator is inserted over the guidewire, slid into the foramen to create adequate working space by manual pressure, and finally fixed in the foramen. This blunt dissection prevents nerve root damage and enables a safe working space by pushing the exiting nerve root away from the surgical field. After correct placement of the obturator in the foramen, a bevel-ended working sheath is inserted over the obturator and is placed on the undersurface of the facet joint.

Endoscopic foraminal unroofing: The main aspect of this step is foraminal unroofing, which refers to the removal of hypertrophic bone structures using specially designed burr and punches under fullendoscopic visualization (Fig. 1B). Initially, the surgeon must discriminate anatomical structures in the foraminal zone. After confirming the position of the exiting nerve root, the surgeon begins to remove the hypertrophic superior facet using endoscopic burr. This endoscopic unroofing should be continued until the foraminal ligament and ligamentum flavum are exposed. After the hypertrophic facet joint is undercut, foraminal structures such as the foraminal ligament, ligamentum flavum, perineural fat covering the exiting nerve root, ventral osteophyte, and disc surface can be seen clearly. The working cannula and endoscope can now be firmly engaged with the widened foraminal portion, allowing sophisticated exploration of the anatomy.
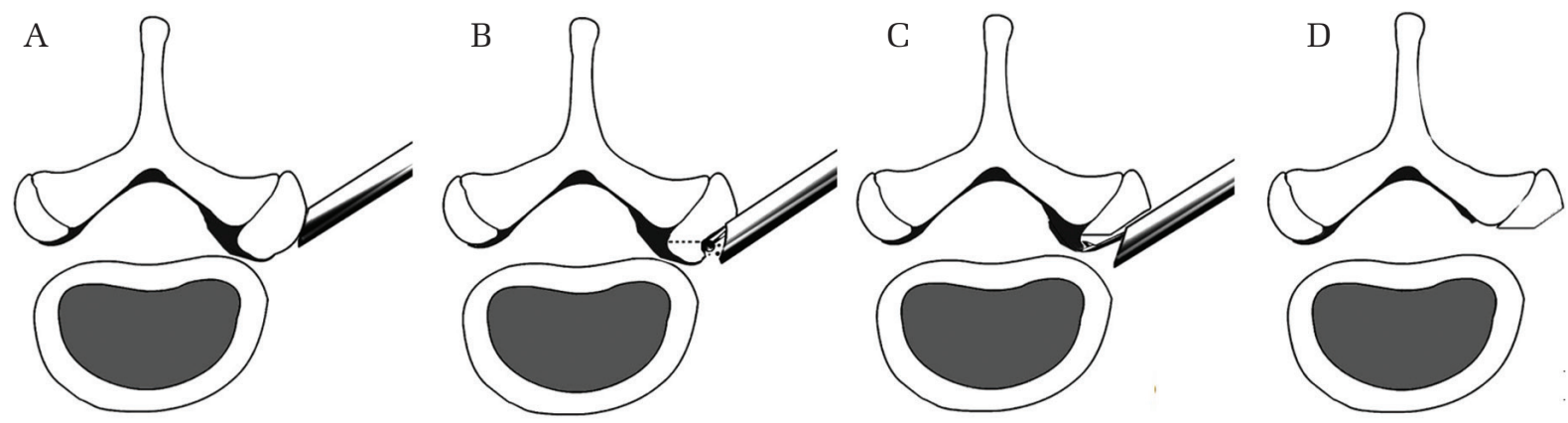

Fig. 1 Schematic illustration of the surgical procedure showing the extraforaminal approach for foraminal decompression (A), foraminal unroofing by using a burr under endoscopic control (B), and full-scale foraminal soft tissue decompression by using various endoscopic instruments (C), resulting in free mobilization of the exiting nerve root (D). 
Full-scale foraminal decompression: The final step is soft tissue removal with or without discectomy and confirmation of free mobilization of the exiting nerve root (Fig. 1C). Endoscopic forceps and micropunches can remove herniated disc, ligamentum flavum, and osteophytes. Flexible forceps and a curved probe can decompress and dissect in all corners of the endoscopic view. A bipolar coagulator (Trigger-Flex; Elliquence, LLC, Baldwin, NY, USA) can be useful for both tissue ablation and hemostasis with navigational access; discectomy is optional, depending on the requirement. After removal of thickened foraminal ligament and ligamentum flavum, the surgeon can see the dural sac and exiting nerve root. Decompressed nerves can rhythmically move depending on pulse, and the presence of remnant disc fragments can be determined by coughing or Valsalva maneuver. The last aspect of this procedure is exposure of the axillar zone and confirmation of free-mobilization of the dural sac and exiting nerve root. The exiting nerve root should be entirely decompressed from the proximal dural sac to the exit-zone on the final endoscopic examination (Fig. 1D).

\section{Measurements}

All pre- and postoperative MRI scans were obtained using the same machine with the same settings (Magnetom Avanto 1.5T; Siemens, Muenchen, Germany). Postoperative MRI was performed in all patients within 24 hours. Two expert evaluators who were independent and blinded to the clinical data measured the various parameters of neuroforamen. All measurements were performed using $\mathrm{T} 1$ and T2-weighted turbo spin-echo sagittal images (TR/ TE, 640/11 for T1-weighted images and 4010/105 for T2-weighted images; slice thickness, $4 \mathrm{~mm}$; slice gap, $0.4 \mathrm{~mm}$; matrix, $512 \times 307$; field of view, $30 \mathrm{~cm}$ ). Various dimensions of neuroforamens were automatically calculated using an electronic cursor via commercially available software (PiView Star; INFINITT, Seoul, Korea). The grade of foraminal stenosis was measured using the four-point MRI grading system at the most stenotic sagittal section. ${ }^{32,33)}$ Grade 0 refers to the absence of foraminal stenosis; grade 1 refers to mild foraminal stenosis showing perineural fat obliteration surrounding the nerve root in the two opposing directions (vertical or transverse). It involves contact with the superior and inferior portions of the nerve root or anterior and posterior portions of the nerve root. No evidence of morphologic change in the nerve root is shown. Grade 2 refers to moderate foraminal stenosis showing perineural fat obliteration surrounding the nerve root in the four directions without morphologic change in both vertical and transverse directions. Grade 3 refers to severe foraminal stenosis showing nerve root collapse or morphologic change (Fig. 2). Quantitative assessments of the neuroforamen were conducted on the basis of T1- and T2-weighted
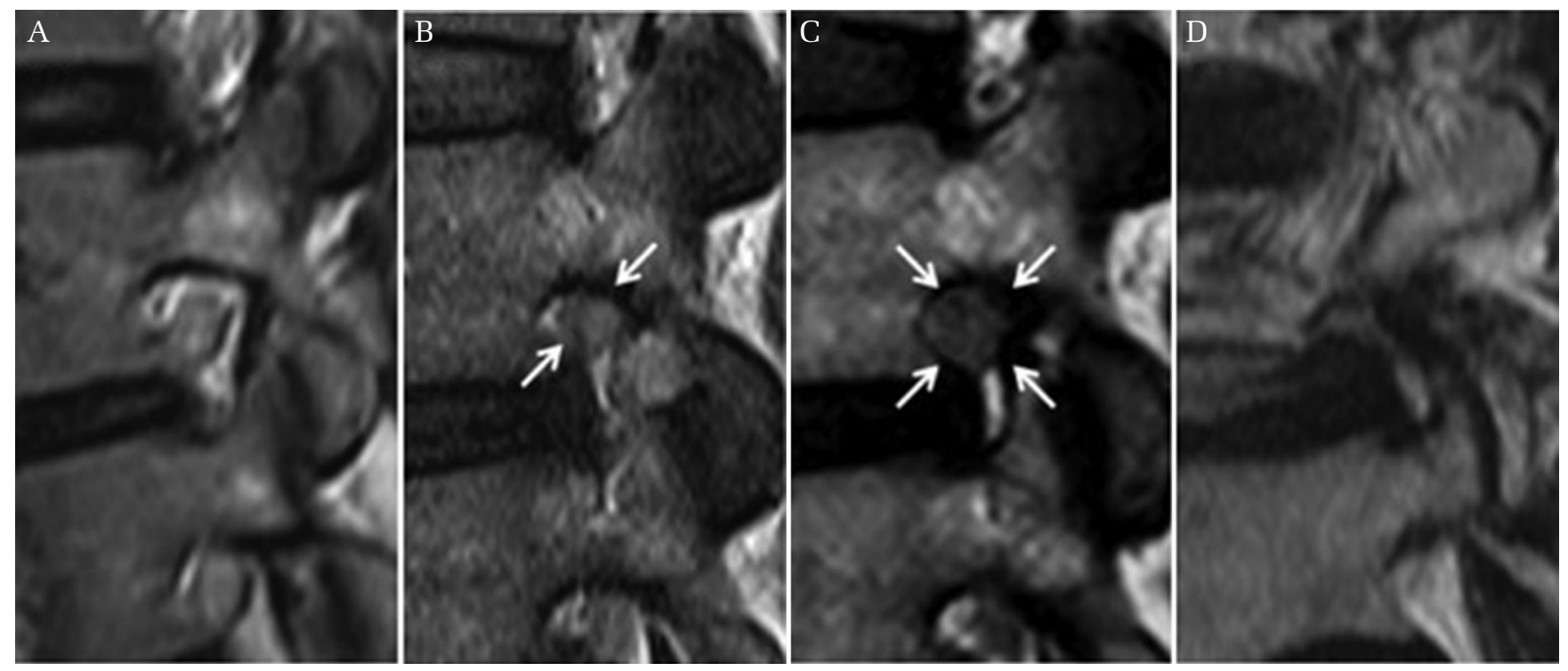

Fig. 2. Grade of foraminal stenosis on T2-weighted sagittal lumbar magnetic resonance images. ${ }^{32)}$ (A) Grade 0 refers to the absence of foraminal stenosis. (B) Grade 1 refers to mild foraminal stenosis showing perineural fat obliteration in two opposing directions (vertical or transverse). (C) Grade 2 refers moderate foraminal stenosis showing perineural fat obliteration in the four directions without morphologic changes in the nerve root. (D) Grade 3 refers to severe foraminal stenosis showing nerve root collapse or morphologic change in the nerve root. 
sagittal MRI scans. ${ }^{34)}$ Foraminal area (FA) refers to the cross-sectional area at the slice that shows the maximum stenosis on sagittal section; foraminal height $(\mathrm{FH})$ refers to the maximum distance between the inferior margin of the pedicle of the superior vertebra and the superior margin of the pedicle of the inferior vertebra; superior foraminal width (SFW) refers to the maximum anteroposterior width in the superior parts of the foramen; middle foraminal width (MFW) refers to the width of the central part of the foramen measured at the level of the middle height of the disc; and posterior disc height (PDH) refers to the shortest distance between the adjacent superior and inferior end plates (Fig. 3). The clinical outcomes were evaluated using the visual analog scale (VAS) for pain, Oswestry disability index (ODI), and modified MacNab criteria.

\section{Analysis}

Statistical analyses were performed using SPSS, Version 18.0 (SPSS Inc., Chicago, IL, USA), and the level of significance was defined by $P<0.05$. Interobserver agreement of the grade of foraminal stenosis was analyzed using kappa statistics. Comparison

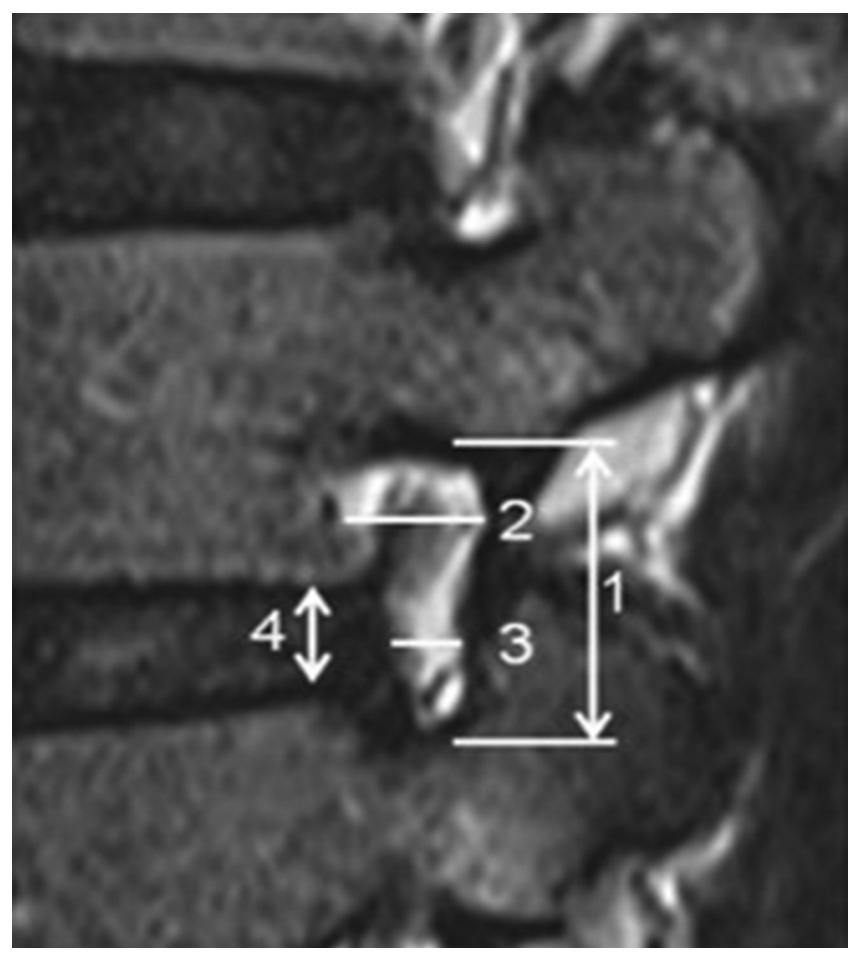

Fig. 3 Measurement of foraminal dimensions on T2-weighted sagittal lumbar magnetic resonance images. ${ }^{34)}$ 1. Foraminal height (FH). 2. Superior foraminal width (SFW). 3. Middle foraminal width (MFW). 4. Posterior disc height (PDH). between pre- and postoperative foraminal parameters was analyzed using $t$-test, Wilcoxon's signed rank test, and intraclass correlation coefficient (ICC).

\section{Results}

\section{Demographics and clinical results}

Study participants included 16 women and 19 men (35 patients) with a mean age of 59.2 years (range, 20-81 years). The operated levels were L3-4 (7), L4-5 (16), and L5-S1 (15) (total = 38 levels). Two patients underwent bilateral procedures, thus 40 neuroforamens were treated and evaluated. Patient demographics are summarized in Table 1. The mean preoperative VAS score for leg pain was $8.4 \pm 0.6$, which decreased to $3.2 \pm 1.1$ at 6 weeks, $2.5 \pm 1.9$ at 6 months, $1.9 \pm 1.3$ at 1 year, and $2.1 \pm 1.5$ at the final follow-up. The mean preoperative VAS score for back pain was $5.2 \pm 0.9$, which decreased to $3.0 \pm 0.7$ at 6 weeks, $2.2 \pm 1.0$ at 6 months, 2.1 \pm 1.0 at 1 year, and $2.0 \pm 1.2$ at the final follow-up. The mean ODI improved from $65.9 \pm 17.1$ at baseline to $32.8 \pm 18.1$ at 6 weeks, $28.3 \pm 16.8$ at 6 months, $19.5 \pm 16.1$ at 1 year, and $19.2 \pm 15.8$ at the final follow-up. Based on modified MacNab criteria, the overall results were as follows: excellent in 14 patients $(40.0 \%)$, good in 18 patients $(51.4 \%)$, fair in 2 patients $(5.7 \%)$, and poor in 1 patient $(2.9 \%)$. Therefore, excellent or good results were obtained in $91.4 \%$ of patients and the rate of symptomatic improvement was $97.1 \%$ (Figs. 4 and 5). Of the two patients with fair outcome, one had grade 2 foraminal stenosis preoperatively, which decreased to grade 0 postoperatively. The other had grade 3 foraminal stenosis preoperatively, which decreased to grade 1 postoperatively. The patient with poor outcome had grade 3 foraminal stenosis

Table 1 Patient demographics

\begin{tabular}{lc}
\hline Variable & No. \\
\hline Patients (no.) & 35 \\
M:F & $19: 16$ \\
Mean age (year) & $59.2(20-81)$ \\
Operated level $(n=38)$ & \\
$\quad$ L3-4 & $7(18.4 \%)$ \\
L4-5 & $16(42.1 \%)$ \\
L5-S1 & $15(39.5 \%)$ \\
Operated neuroforamen & 40 \\
Mean operation time $(\mathrm{min})$ & $58.7(20-135)$ \\
Mean hospital stay $(\mathrm{days})$ & $2.2(1-23)$ \\
BMI Body mass index $\left(\mathrm{kg} / \mathrm{m}^{2}\right)$ & $23.98(16.65-28.33)$ \\
\hline
\end{tabular}




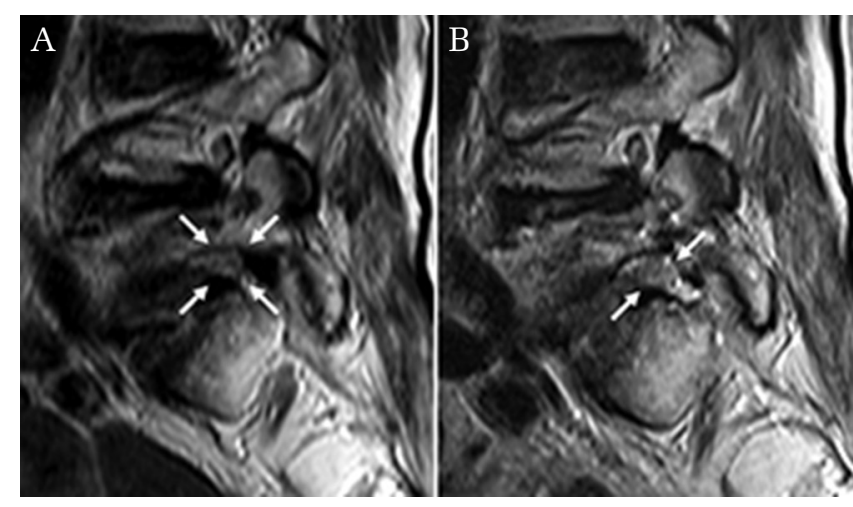

Fig. 4. Illustrated case of an 81-year-old female patient. Preoperative T2-weighted sagittal magnetic resonance image showing severe foraminal stenosis (grade 3) at L5-S1 level on the right side (A). Postoperative T2-weighted sagittal magnetic resonance image showing full-scale foraminal decompression (grade 1) after percutaneous endoscopic lumbar foraminotomy (B).

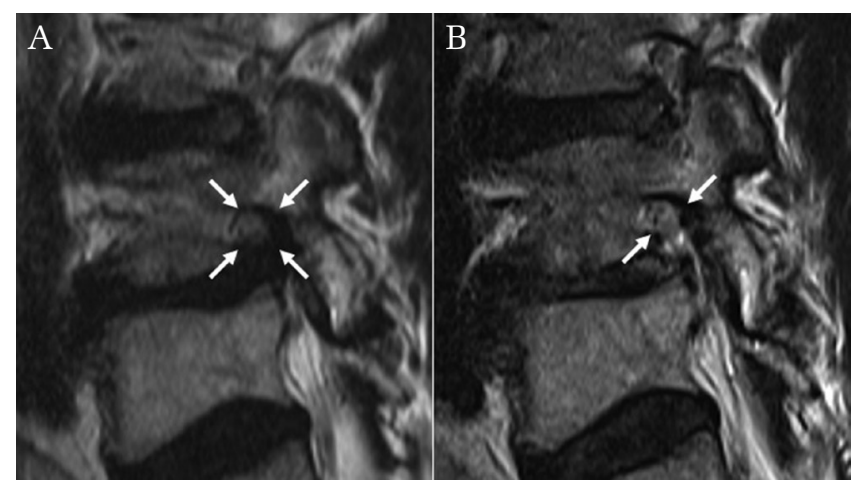

Fig. 5. Illustrated case of a 67-year-old male patient. Preoperative T2-weighted sagittal magnetic resonance image showing severe foraminal stenosis with disc herniation at L4-5 level on the right side (A). Postoperative T2-weighted sagittal magnetic resonance image showing full-scale foraminal decompression (grade 1) after percutaneous endoscopic lumbar foraminotomy (B). preoperatively, which decreased to grade 1 postoperatively. The global clinical outcome was not related to the grade of foraminal stenosis in our study $(P>0.1)$.

\section{Grade of foraminal stenosis}

Changes of the foraminal stenosis grade of each neuroforamen were evaluated by two observers based on the Lee grading system. ${ }^{32)}$ Preoperative grades were grade $2(35 \%)$ or grade $3(65 \%)$, and postoperative grades were grade $0(26.25 \%)$ or grade $1(73.75 \%)$ (Table 2). The mean values of observer 1 changed from $2.58 \pm 0.50$ to $0.55 \pm 0.55$. Those of observer 2 changed from $2.68 \pm 0.53$ to 0.80 \pm 0.46 . The average value of foraminal stenosis grade improved from $2.63 \pm 0.51$ to $0.68 \pm 0.52$. The level of interobserver agreement was good $(0.80 \geq k$-value $>0.60)$; the preoperative $k$-value was 0.678 and the postoperative $k$-value was 0.679 (Fig. 3, Table 3).

\section{Foraminal area}

The mean FA of observer 1 increased from $46.11 \pm$ $26.60 \mathrm{~mm}^{2}$ to $84.98 \pm 37.64 \mathrm{~mm}^{2}(P<0.001)$, while

Table 3 Interobserver agreement of grade of foraminal stenosis $(n=40)$

\begin{tabular}{lcc}
\hline $\begin{array}{l}\text { Measurement* } \\
(\text { Mean } \pm \text { SD) }\end{array}$ & Preoperative & Postoperative \\
\hline Observer 1 & $2.58 \pm 0.50$ & $0.55 \pm 0.55$ \\
Observer 2 & $2.68 \pm 0.53$ & $0.80 \pm 0.46$ \\
Average & $2.63 \pm 0.51$ & $0.68 \pm 0.52$ \\
$k$ & 0.678 (good) & 0.679 (good) \\
$p$ & $<0.001$ & $<0.001$ \\
\hline
\end{tabular}

* Data from Lee et al. ${ }^{32)}$ Statistical analysis: Reliability analysis (kappa coefficient), Strength of interobserver agreement: $k>0.80$ (very good), $0.80 \geq k>0.60$ (good), $0.60 \geq k>0.40$ (moderate), $0.40 \geq k>0.20$ (fair), $k \leq 0.20$ (poor).

Table 2 Qualitative assessment of the neuroforamen on MRI: pre- and postoperative grade of foraminal stenosis ( $n=40)$

\begin{tabular}{|c|c|c|c|c|c|c|}
\hline $\begin{array}{l}\text { Measurement } \\
(\text { Lee's grade*) }\end{array}$ & Status & Grade 0 & Grade 1 & Grade 2 & Grade 3 & Total \\
\hline Observer 1 & Preoperative & 0 & 0 & 17 & 23 & 40 \\
\hline \multirow[t]{2}{*}{ Observer 2} & Preoperative & 0 & 0 & 11 & 29 & 40 \\
\hline & Postoperative & 9 & 31 & 0 & 0 & 40 \\
\hline Average & Postoperative & $10.5(26.25 \%)$ & $29.5(73.75 \%)$ & 0 & 0 & $40(100 \%)$ \\
\hline
\end{tabular}

*Data from Lee et al. ${ }^{32)}$ 
those of observer 2 increased from $53.98 \pm 23.65$ $\mathrm{mm}^{2}$ to $99.07 \pm 33.90 \mathrm{~mm}^{2}(P<0.001)$. The average value of both observers for FA increased from 50.05 $\pm 5.56 \mathrm{~mm}^{2}$ to $92.03 \pm 9.96 \mathrm{~mm}^{2}(P<0.001)$. The level of ICC was excellent (0.863) in the preoperative measurement and good (0.704) in the postoperative measurement (Table 4).

\section{Foraminal height and width}

The mean FH of observer 1 increased from $9.96 \pm$ $4.91 \mathrm{~mm}$ to $13.18 \pm 3.74 \mathrm{~mm}$, and that of observer 2 increased from $12.76 \pm 10.97 \mathrm{~mm}$ to $13.75 \pm 3.35$ $\mathrm{mm}$. The average value of both observers for $\mathrm{FH}$ increased from $11.36 \pm 1.98 \mathrm{~mm}$ to $13.47 \pm 0.40$ $\mathrm{mm}(P<0.001)$. The preoperative level of ICC was excellent $(0.847)$, as was the postoperative level of ICC (0.823). The mean SFW of observer 1 increased from $5.90 \pm 3.14 \mathrm{~mm}$ to $8.46 \pm 3.40 \mathrm{~mm}$ and those of observer 2 increased from $6.96 \pm 2.56$ $\mathrm{mm}$ to $10.08 \pm 3.03 \mathrm{~mm}$. The average value of both observers for SFW increased from $6.43 \pm 0.75 \mathrm{~mm}$ to $9.27 \pm 1.15 \mathrm{~mm}(P<0.001)$. The preoperative level of ICC was good (0.685) and the postoperative level of ICC was fair (0.516). The mean MFW of observer 1 increased from $1.07 \pm 1.47 \mathrm{~mm}$ to 4.00 $\pm 3.36 \mathrm{~mm}$ and that of observer 2 increased from $1.87 \pm 2.25 \mathrm{~mm}$ to $5.57 \pm 3.19 \mathrm{~mm}$. The average value of both observers for MFW increased from
$1.47 \pm 0.57 \mathrm{~mm}$ to $4.78 \pm 1.12 \mathrm{~mm}(P<0.001)$. The preoperative level of ICC was good (0.784) and the postoperative level of ICC was also good (0.617). In contrast, the disc height was unchanged. The average posterior disc height of both observers changed from $6.64 \mathrm{~mm}$ to $6.60 \mathrm{~mm}$; these changes were not statistically significant (Tables 4 and 5).

\section{Discussion}

\section{Qualitative analysis: grades of foraminal stenosis}

We applied the MRI sagittal view in our qualitative evaluation of foraminal decompression due to the following reasons. First, MRI is the best imaging study for nerve root compression by various soft tissues, such as ligament flavum, foraminal ligaments, and redundant disc. ${ }^{29,35,36)}$ Second, although computed tomography (CT) scan is superior to MRI with respect to bony structures, there is no other objective or qualitative measurement tools using a CT scan for evaluating lumbar foraminal stenosis. Our data showed that postoperative MRI can reflect the decompression status in both qualitative and quantitative manners, despite the possibility of perineural fat tissue removal during the decompression process. There are two representative MRI grading systems of lumbar foraminal stenosis based on sagittal images.

Table 4 Quantitative assessment of the neuroforamen on MRI: pre- and post-operative foraminal parameters ( $n=40)$

\begin{tabular}{llccccc}
\hline $\begin{array}{l}\text { Measurement* } \\
\text { (Mean } \pm \text { SD) }\end{array}$ & Status & FA $\left(\mathrm{mm}^{2}\right)$ & FH $(\mathrm{mm})$ & SFW $(\mathrm{mm})$ & MFW (mm) & PDH (mm) \\
\hline Observer 1 & Preop & $46.11 \pm 26.60$ & $9.96 \pm 4.91$ & $5.90 \pm 3.14$ & $1.07 \pm 1.47$ & $6.39 \pm 2.34$ \\
& Postop & $84.98 \pm 37.64$ & $13.18 \pm 3.74$ & $8.46 \pm 3.40$ & $4.00 \pm 3.36$ & $6.50 \pm 2.41$ \\
Observer 2 & Preop & $53.98 \pm 23.65$ & $12.76 \pm 10.97$ & $6.96 \pm 2.56$ & $1.87 \pm 2.25$ & $6.89 \pm 2.36$ \\
& Postop & $99.07 \pm 33.90$ & $13.75 \pm 3.35$ & $10.08 \pm 3.03$ & $5.57 \pm 3.19$ & $6.69 \pm 2.36$ \\
Average & Preop & $50.05 \pm 5.56$ & $11.36 \pm 1.98$ & $6.43 \pm 0.75$ & $1.47 \pm 0.57$ & $6.64 \pm 0.35$ \\
& Postop & $92.03 \pm 9.96$ & $13.47 \pm 0.40$ & $9.27 \pm 1.15$ & $4.78 \pm 1.12$ & $6.60 \pm 0.13$ \\
\hline
\end{tabular}

*Data from Attias et al. ${ }^{34)}$ FA: indicates foraminal area, FH: foraminal height, MFW: middle foraminal width, PDH: posterior disc height, SFW: superior foraminal width.

Table 5 Interobserver agreement of foraminal parameters $(n=40)$

\begin{tabular}{lcccccc}
\hline Measurement* & Status & FA & FH & SFW & MFW & PDH \\
\hline ICC & Preop & 0.863 & 0.847 & 0.685 & 0.784 & 0.864 \\
$(95 \%$ CI $)$ & & $(0.740-0.927)$ & $(0.711-0.919)$ & $(0.405-0.834)$ & $(0.591-0.886)$ & $(0.743-0.928)$ \\
ICC & Postop & 0.704 & 0.823 & 0.516 & 0.617 & 0.898 \\
$(95 \%$ CI $)$ & & $(0.440-0.843)$ & $(0.665-0.906)$ & $(0.085-0.744)$ & $(0.275-0.797)$ & $(0.807-0.946)$ \\
\hline
\end{tabular}

${ }^{*}$ Data from Attias et al ${ }^{34)}$ ICC > 0.80: excellent, $0.80 \geq$ ICC > 0.60: good, $0.60 \geq$ ICC > 0.40: fair, ICC $\leq 0.40$ : poor, CI: confidence interval, FA: foraminal area, FH: foraminal height, ICC: intraclass correlation coefficient, MFW: middle foraminal width, PDH: posterior disc height, SFW: superior foraminal width. 
The Wildermuth system ${ }^{31)}$ mainly focuses on the degree of epidural fat obliteration, whereas the Lee system $^{32)}$ considers both the amount of fat obliteration and the presence of exiting nerve root compression. The interobserver reliability of both systems is similar. ${ }^{33)}$ We used the Lee system because it is better in evaluating the surgical change in the compressed exiting nerve root after the decompression procedure. The preoperative foraminal grades were either grade 2 or grade 3 , which means the surgical indications were moderate to severe foraminal stenosis, not mild or dynamic problems. The postoperative foraminal grades were either grade 1 or grade 2 . All cases demonstrated improvement in foraminal stenosis grades. The mean value of foraminal stenosis grade also significantly improved from 2.63 to 0.68 . These changes in foraminal grade mean that definitive decompression of the exiting nerve root may be proven not only by subjective symptoms, but also by objective radiographic images.

\section{Quantitative analysis: foraminal dimensions}

There are few quantitative studies on direct foraminal decompression. Some cadaveric data for radiographic changes after foraminal decompression have been published. ${ }^{37,38)}$ For example, Musacchio et al. ${ }^{37)}$ described a minimally invasive lumbar laminectomy via a dual-tube technique. They reported an average $30.8 \%$ increase in FA after microscopic decompression. Evins et al. ${ }^{38)}$ performed a cadaveric study evaluating the radiographic outcome of endoscopic lumbar foraminotomy. The authors state that endoscopic lumbar foraminotomy achieved an average $56.1 \%$ increase in $\mathrm{FA}$ and an average $24.3 \%$ increase in $\mathrm{FH}$.

We quantitatively measured the dimensions of the neuroforamen in various aspects. All parameters for foraminal dimensions, including FA, FH, SFW, and MFW, consistently increased after surgery. The mean FA significantly increased from $50.05 \mathrm{~mm}^{2}$ to $92.03 \mathrm{~mm}^{2}$ (83.9\% increase), an improvement comparable to that reported in cadaveric studies. ${ }^{37,38)}$ Other foraminal dimensions also increased: the mean FH significantly increased from $11.36 \mathrm{~mm}$ to $13.47 \mathrm{~mm}$ (18.6\% increase); the mean SFW significantly increased from $6.43 \mathrm{~mm}$ to $9.27 \mathrm{~mm}$ ( $44.2 \%$ increase); and the mean MFW significantly increased from $1.47 \mathrm{~mm}$ to $4.78 \mathrm{~mm}$ $(221.2 \%$ increase). In contrast, the disc height remained unchanged because the disc had coagulated or only extruded fragments, if any, were removed when preserving the maternal disc. An increase in the dimensions of the neuroforamen in all aspects indicated that a full-scale foraminal decompression was efficiently achieved.
In our quantitative data, the values of increase differed among foraminal parameters. The most notable increase was observed in MFW, with a $221.2 \%$ increase, while $\mathrm{FH}$ increased by $18.6 \%$. We postulate that this phenomenon is related to the surgical technique of ELF. That is, the transforaminal approach and main decompression process are usually performed at the level of redundant disc and the tip of the hypertrophic superior facet. Therefore, the decompression effect may be maximal in MFW. In contrast, FH was relatively less affected by ELF. Partial resection of the upper or lower pedicle as well as soft tissue removal with endoscopic instruments can increase FH. We postulate that the foraminal decompression of the ELF technique may be more focused in the anteroposterior direction at the disc level rather than in the craniocaudal direction.

\section{Interobserver agreement}

In this study, pre- and postoperative foraminal parameters showed high interobserver agreement. There was good interobserver agreement for qualitative MRI grading score for severity of foraminal stenosis. Regarding the quantitative MRI measurements, there was also good to excellent interobserver agreement. The levels of concordance for all preoperative foraminal parameters, including FA, FH, FW, and PDH, were good or excellent. Levels for postoperative foraminal parameters were also good or excellent, with the exception of postoperative SFW, which was fair. The results of both our qualitative and quantitative evaluations showed that effective foraminal decompression can be obtained by the ELF technique.

\section{Limitations of the study and future perspective}

The current study has some limitations. First, the MRI scans were taken in a static supine position; no data for axial-loading or dynamic MRI were collected. Therefore, we could not evaluate the real foraminal parameters in various conditions such as upright stance, flexion/extension, or lateral bending. Second, all MRI scans were obtained at the early postoperative stage. In general, early-postoperative MRI after open lumbar surgery may be affected by changes in postoperative tissues. However, the PELF technique is a percutaneous procedure that preserves the paravertebral muscles, lamina, and intracanalicular epidural space. Therefore, postoperative changes of the surrounding tissues may be minimal. In fact, recent articles regarding the endoscopic lumbar foraminal decompression technique demonstrated the early postoperative MRI evaluating the postoperative changes. ${ }^{29,36)}$ Finally, no control group was used, so our study could 
not establish the clinical effectiveness of ELF. We aimed to describe a minimally invasive endoscopic foraminotomy technique and to demonstrate the radiographic efficacy on MRI. Our future work will focus on a randomized controlled study comparing ELF and open foraminotomy.

\section{Conclusion}

According to previous studies, ELF is clinically efficacious for lumbar foraminal stenosis. In this radiographic study, the grade of foraminal stenosis and foraminal dimensions were significantly improved. These data indicate that this minimally invasive endoscopic technique can mechanically decompress the neural foramen.

\section{Acknowledgment}

The authors express special thanks to Soo-Kyung Park and Je-Min Son for preparing the figures.

\section{Conflicts of Interest Disclosure}

The authors declare no conflicts of interest.

\section{References}

1) Reulen HJ, Pfaundler S, Ebeling U: The lateral microsurgical approach to the "extracanalicular" lumbar disc herniation. I: A technical note. Acta Neurochir (Wien) 84: 64-67, 1987

2) Wiltse LL, Spencer CW: New uses and refinements of the paraspinal approach to the lumbar spine. Spine 13: 696-706, 1988

3) Chang SB, Lee SH, Ahn Y, Kim JM: Risk factor for unsatisfactory outcome after lumbar foraminal and far lateral microdecompression. Spine 31: 1163-1167, 2006

4) Kunogi J, Hasue M: Diagnosis and operative treatment of intraforaminal and extraforaminal nerve root compression. Spine 16: 1312-1320, 1991

5) Donaldson WF, Star MJ, Thorne RP: Surgical treatment for the far lateral herniated lumbar disc. Spine 18: 1263-1267, 1993

6) Lejeune JP, Hladky JP, Cotten A, Vinchon M, Christiaens JL: Foraminal lumbar disc herniation. Experience with 83 patients. Spine 19: 1905-1908, 1994

7) Darden BV, Wade JF, Alexander R, Wood KE, Rhyne AL, Hicks JR: Far lateral disc herniations treated by microscopic fragment excision. Techniques and results. Spine 20: 1500-1505, 1995

8) Baba H, Uchida K, Maezawa Y, Furusawa N, Okumura Y, Imura S: Microsurgical nerve root canal widening without fusion for lumbosacral intervertebral foraminal stenosis: technical notes and early results. Spinal Cord 34: 644-650, 1996
9) Hodges SD, Humphreys SC, Eck JC, Covington LA: The surgical treatment of far lateral L3-L4 and L4-L5 disc herniations. A modified technique and outcomes analysis of 25 patients. Spine 24: 1243-1246, 1999

10) Gioia G, Mandelli D, Capaccioni B, Randelli F, Tessari L: Surgical treatment of far lateral lumbar disc herniation. Identification of compressed root and discectomy by lateral approach. Spine 24: 1952-1957, 1999

11) Epstein NE: Foraminal and far lateral lumbar disc herniations: surgical alternatives and outcome measures. Spinal Cord 40: 491-500, 2002

12) Chang HS, Zidan I, Fujisawa N, Matsui T: Microsurgical posterolateral transmuscular approach for lumbar foraminal stenosis. J Spinal Disord Tech 24: 302-307, 2011

13) Garrido E, Connaughton PN: Unilateral facetectomy approach for lateral lumbar disc herniation. J Neurosurg 74: 754-756, 1991

14) Jenis LG, An HS: Spine update. Lumbar foraminal stenosis. Spine 25: 389-394, 2000

15) Knight MT, Vajda A, Jakab GV, Awan S: Endoscopic laser foraminoplasty on the lumbar spine-early experience. Minim Invasive Neurosurg 41: 5-9, 1998

16) Knight MT, Goswami A, Patko JT, Buxton N: Endoscopic foraminoplasty: a prospective study on 250 consecutive patients with independent evaluation. J Clin Laser Med Surg 19: 73-81, 2001

17) Knight M, Goswami A: Management of isthmic spondylolisthesis with posterolateral endoscopic foraminal decompression. Spine (Phila Pa 1976) 28: 573-581, 2003

18) Ahn Y, Lee SH, Park WM, Lee HY: Posterolateral percutaneous endoscopic lumbar foraminotomy for L5-S1 foraminal or lateral exit zone stenosis. Technical note. J Neurosurg 99 (3 Suppl): 320-323, 2003

19) Yeung AT, Yeung CA: Advances in endoscopic disc and spine surgery: foraminal approach. Surg Technol Int 11: 255-263, 2003

20) Jang JS, An SH, Lee SH: Transforaminal percutaneous endoscopic discectomy in the treatment of foraminal and extraforaminal lumbar disc herniations. J Spinal Disord Tech 19: 338-343, 2006

21) Kambin P, O’Brien E, Zhou L, Schaffer JL: Arthroscopic microdiscectomy and selective fragmentectomy. Clin Orthop Relat Res (347): 150-167, 1998

22) Ahn Y, Lee SH, Park WM, Lee HY, Shin SW, Kang HY: Percutaneous endoscopic lumbar discectomy for recurrent disc herniation: surgical technique, outcome, and prognostic factors of 43 consecutive cases. Spine (Phila Pa 1976) 29: E326-E332, 2004.

23) Ruetten S, Komp M, Godolias G: An extreme lateral access for the surgery of lumbar disc herniations inside the spinal canal using the full-endoscopic uniportal transforaminal approach-technique and prospective results of 463 patients. Spine 30: 2570-2578, 2005 
24) Ahn Y: Transforaminal percutaneous endoscopic lumbar discectomy: technical tips to prevent complications. Expert Rev Med Devices 9: 361-366, 2012

25) Mayer HM, Brock M: Percutaneous endoscopic discectomy: surgical technique and preliminary results compared to microsurgical discectomy. J Neurosurg 78: 216-225, 1993

26) Hermantin FU, Peters T, Quartararo L, Kambin P: A prospective, randomized study comparing the results of open discectomy with those of videoassisted arthroscopic microdiscectomy. J Bone Joint Surg Am 81: 958-965, 1999

27) Hoogland T, Schubert M, Miklitz B, Ramirez A: Transforaminal posterolateral endoscopic discectomy with or without the combination of a low-dose chymopapain: a prospective randomized study in 280 consecutive cases. Spine 31: E890-E897, 2006

28) Ruetten S, Komp M, Merk H, Godolias G: Fullendoscopic interlaminar and transforaminal lumbar discectomy versus conventional microsurgical technique: a prospective, randomized, controlled study. Spine 33: 931-939, 2008

29) Ahn Y, Oh HK, Kim H, Lee SH, Lee HN: Percutaneous endoscopic lumbar foraminotomy: an advanced surgical technique and clinical outcomes. Neurosurgery 75: 124-133; discussion 132-133, 2014

30) Ahn Y: Percutaneous endoscopic decompression for lumbar spinal stenosis. Expert Rev Med Devices 11: 605-616, 2014

31) Wildermuth S, Zanetti M, Duewell S, et al.: Lumbar spine: quantitative and qualitative assessment of positional (upright flexion and extension) MR imaging and myelography. Radiology 207: 391-398, 1998
32) Lee S, Lee JW, Yeom JS, et al.: A practical MRI grading system for lumbar foraminal stenosis. AJR Am J Roentgenol 194: 1095-1098, 2010

33) Park HJ, Kim SS, Lee SY, et al.: Clinical correlation of a new MR imaging method for assessing lumbar foraminal stenosis. AJNR Am J Neuroradiol 33: 818-822, 2012

34) Attias N, Hayman A, Hipp JA, Noble P, Esses SI: Assessment of magnetic resonance imaging in the diagnosis of lumbar spine foraminal stenosis-a surgeon's perspective. J Spinal Disord Tech 19: 249-256, 2006

35) Cho W, Sokolowski MJ, Mehbod AA, et al.: MRI measurement of neuroforaminal dimension at the index and supradjacent levels after anterior lumbar interbody fusion: a prospective study. Clin Orthop Surg 5: 49-54, 2013

36) Li ZZ, Hou SX, Shang WL, Song KR, Zhao HL: Modified percutaneous lumbar foraminoplasty and percutaneous endoscopic lumbar discectomy: instrument design, technique notes, and 5 years follow-up. Pain Physician 20: E85-E98, 2017

37) Musacchio M, Patel N, Bagan B, Deutsch H, Vaccaro AR, Ratliff J: Minimally invasive lumbar laminectomy via a dual-tube technique: evaluation in a cadaver model. Surg Neurol 67: 348-352, 2007

38) Evins AI, Banu MA, Njoku I, et al.: Endoscopic lumbar foraminotomy. J Clin Neurosci 22: 730-734, 2015

Address reprint requests to: Yong Ahn, MD, PhD, Department of Neurosurgery, Gachon University Gil Medical Center, 21 Namdong-daero 774 beon-gil, Namdong-gu, Incheon, 21565, Korea.

e-mail: ns-ay@hanmail.net 